\title{
O PRINCÍPIO DA COOPERAÇÃO NO PROCESSO TRIBUTÁRIO: UMA REFLEXÃO SOBRE FAIR PLAY JURÍDICO
}

Sidney Stahl

\section{INTRODUÇÃO}

Uma frase citada pelo Barão de Coubertin, ${ }^{1}$ o fundador dos Jogos Olímpicos da era moderna, originalmente proferida na missa para os participantes dos Jogos Olímpicos de Londres, em 1908, na catedral de São Paulo pelo bispo anglicano da Pensilvânia, afirma que "O importante na vida não é o triunfo, mas o combate; o essencial não é ter vencido, mas ter lutado bem". Essa é a essência, no entendimento do ilustre Barão, do chamado fair play.

O termo já foi incorporado aos dicionários da língua portuguesa e significa, na essência, competir de modo limpo (literalmente, "jogo limpo"). Fair play não é uma regra expressa nos códigos esportivos ou uma determinação obrigatória nas competições, é uma filosofia de comportamento, uma regra ética de conduta, ou melhor, o conceito de fair play está vinculado à ética no meio esportivo. Os praticantes devem procurar jogar de maneira justa, não prejudicando o adversário de forma proposital.

Fair play é, antes de tudo, um conceito ético que pode ser aplicado a qualquer atividade na qual se persiga justiça (fair significa “justo”), ou seja, a qualquer atividade na qual se busque alcançar a justiça em situações de confronto,

1 COUBERTIN, Pierre de. Olimpismo: seleção de textos. Porto Alegre: ediPUCRS, 2015. p. 581. 
quer seja um confronto esportivo, quer seja o confronto de ideias, quer seja o confronto jurídico.

Em relação aos confrontos jurídicos, esses se fazem nos processos, que são geridos pelas regras do Código de Processo Civil (CPC). A Lei n. 13.105, de 16 de março de 2015, conhecida como Novo Código de Processo Civil (NCPC), é uma tentativa de tornar o processo mais eficiente, como se pode constatar do seguinte trecho de sua exposição de motivos: ${ }^{2}$

Sem prejuízo da manutenção e do aperfeiçoamento dos institutos introduzidos no sistema pelas reformas ocorridas nos anos de 1.992 até hoje, criou-se um Código novo, que não significa, todavia, uma ruptura com o passado, mas um passo à frente. Assim, além de conservados os institutos cujos resultados foram positivos, incluíram-se no sistema outros tantos que visam a atribuir-lhe alto grau de eficiência.

O NCPC é inaugurado apontando que se rege pelos valores e pelas normas fundamentais estabelecidas na Constituição, e é assim que se expressa o seu art. $1^{\circ}$ :

Art. $1^{\circ}$. O processo civil será ordenado, disciplinado e interpretado conforme os valores e as normas fundamentais estabelecidos na Constituição da República Federativa do Brasil, observando-se as disposições deste Código.

No seu art. $6^{\circ}$, o NCPC introduziu o princípio da cooperação, que passa a compor os róis de princípios norteadores do direito pátrio. Usamos a expressão no plural - róis - porque no substrato jurídico nacional temos outros princípios apontados a partir da Constituição, mas que se encontram também nas demais normas legais. O referido artigo estabelece que "todos os sujeitos do processo devem cooperar entre si para que se obtenha, em tempo razoável, decisão de mérito justa e efetiva", introduzindo o modelo cooperativo por meio de uma norma geral, inspirado no modelo constitucional, conforme assevera Cassio Scarpinella Bueno. ${ }^{3}$

$\mathrm{Na}$ realidade, o NCPC estabelece o fair play na disputa processual. Cooperação em termos processuais implica diminuir a litigiosidade e aumentar a transparência

2 Disponivel em: <http://www.senado.gov.br/senado/novocpc/pdf/Anteprojeto.pdf>. Acesso em: 18 out. 2016.

3 BUENO, Cassio Scarpinella Bueno. Novo Código de Processo Civil Anotado. São Paulo: Saraiva, 2015. p. 45. 
entre as partes. Os objetivos são os traçados no artigo: justiça, efetividade e celeridade. Não há na norma processual qualquer sanção específica à falta de cooperação, mas é princípio e servirá ao magistrado para provocar-lhe o convencimento.

Voltando ao Barão de Coubertin, ${ }^{4}$ há um trecho do discurso proferido no jantar oferecido pelo governo britânico em 24 de julho, em Londres, que vale destacar:

A ideia Olímpica é ao nosso ver a concepção de uma cultura avançada, apoiada, por um lado, no espírito cavalheiresco que vocês tão graciosamente chamam de fair play, e por outro, na noção estética, no culto ao que é belo e gracioso. Não direi que os antigos não tenham faltado com esse ideal alguma vez. Essa manhã lia em um de seus grandes periódicos, a propósito de um incidente ocorrido ontem que causou certa inquietação, uma expressão de desalento ao pensar que certos traços de nossos costumes esportivos atuais nos impediam aspirar a alcançar o nível clássico. Ah, senhores! Vocês acreditam que incidentes como esses não têm manchado a crônica dos Jogos Olímpicos, Píticos, Nemeos, de todas as grandes reuniões desportivas da antiguidade? Seria ingênuo pretender isso. O homem sempre foi apaixonado, e que os céus nos preservem de uma sociedade na qual não haja excessos e na qual a expressão dos sentimentos ardentes se encerre nos moldes demasiado estreitos das conveniências.

Pode-se dizer, portanto, que em nossos dias, nos quais o progresso da civilização material (eu acrescentaria, o da civilização mecânica) tem louvado todas as coisas, existem alguns caprichos que ameaçam a ideia Olímpica, que produzem inquietações. Se, não quero em absoluto ocultar isso, o fair play está em perigo; e o está sobretudo em razão do desenvolvimento desse câncer ao qual se têm permitido expandir-se imprudentemente: a loucura do jogo, da aposta, do gambling.

O que aponta com propriedade o Barão é que a existência de um confronto com implicações patrimoniais põe em perigo o fair play, por óbvio! Então, somos pessimistas do mesmo modo, no mínimo para iniciar a nossa análise: como vislumbrar a lealdade e a cooperação de advogados e procuradores nos processos nos quais se discutem tributos?

A ideia de fair play está ligada à noção de moralidade. O uso que os atores sociais fazem do termo, dentro de um jogo e até mesmo fora dele, remete a uma

4 COUBERTIN, Pierre de. Olimpismo: seleção de textos. Porto Alegre: ediPUCRS, 2015. p. 580. 
série de noções que, apesar de não estarem explicitamente presentes nas regras, são compreendidas por aqueles que compartilham de um respeito ao próprio jogo. Fair play significa mais que seguir as regras: significa colaborar para que elas sejam cumpridas, mesmo se contrárias a si mesmo.

Mas há de se duvidar desse espírito de cooperação entre a Fazenda e o contribuinte, a não ser que a falta de cooperação implique em alguma sanção; porém, a sanção não está expressa na norma. Assim, o que vamos examinar no decorrer dessas poucas páginas - impostas mais por exigência dos limites da obra que em face do meu próprio interesse - são os elementos que tornam possíveis ou impossíveis certas formas de colaboração no processo e a sua efetividade.

\section{ELEMENTOS DA OBRIGAÇÃO DE COOPERAÇÃO}

Conforme apontamos, o art. $6^{\circ}$ do NCPC obriga todos os sujeitos do processo a cooperarem entre si para que se obtenha decisão de mérito justa, efetiva e célere. Por outro lado, a obrigação incide sobre atores que têm perspectivas concorrentes.

Essa cooperação, portanto, é uma obrigação intersubjetiva vista das diversas perspectivas de ética e moral e pode ser representada em relação à forma (a obrigação de se respeitar a regra do jogo ou do processo), em relação ao meio (a obrigação de não agir contra o processo, produzindo atos que impeçam ou dificultem o seu andamento), ou ainda em relação ao objeto (a necessidade de transparência).

Não se pode confundir o princípio da cooperação (norma) com a exigência em se cooperar (elemento subjetivo). A cooperação como elemento do processo é uma norma que impõe condutas. Assim, para que se configure o ilícito processual, a falta de cooperação precisa ser traduzida em um suporte fático, mesmo que omissivo. Essas condutas se manifestam nos atos processuais que implicam a contraposição dos objetivos traçados pelo art. $6^{\circ}$ : a justiça, a efetividade e a celeridade.

Portanto, por mais que seja difícil apontar quais são os elementos da obrigação de se cooperar, é possível apontar quais são os atos que se opõem ao dever de cooperar: atos que impliquem em postergação ou protelação desnecessários, condutas que impeçam que se pronuncie a decisão de mérito e atos que impeçam a atividade satisfativa, que é o fim a ser alcançado pelo próprio processo.

$\mathrm{O}$ que o processo exige, a partir da imposição constante do art. $6^{\circ}$ de cooperação entre as partes, é que as partes atuem de maneira não desconexa com o objeto da demanda e que sejam, dentro dos limites constitucionais, transparentes, evitando-se surpresas para a parte contrária e para o juiz. Justo, nesses casos, é que 
as partes tenham informações simétricas, ou seja, que aquilo que é sabido por uma das partes seja conhecido pelas demais.

Entretanto, essa obrigação de compartilhar informações está limitada no direito de não produzir prova contra si mesmo, por isso, a parte está obrigada a apresentar as informações de que dispõe sobre algo que possa interferir no processo, ou a permitir o acesso a tais elementos, desde que não implique em produção de prova contra si mesmo, ou que prejudique sua própria defesa.

A questão se assemelha às discussões acerca da igualdade de informações constantes da análise econômica do direito, ou melhor, às discussões acerca da assimetria de informações nas relações contratuais e nas relações concorrenciais ou regulatórias. Essa assimetria de informações é tratada pela doutrina na análise de situações anteriores e posteriores à formação do vínculo relacional. Esse vínculo poderia ser um contrato, uma concorrência pública ou qualquer outro fato jurídico que implique em confronto de perspectivas concorrentes.

A análise econômica do direito tratou de separar as situações anteriores e posteriores à conexão e denominou a assimetria de informações de "seleção adversa", se ocorrida anteriormente, e de "risco moral", se posterior à formação do vínculo. No caso da sua aplicação ao processo civil, teremos, salvo algum engano desse autor, assimetrias de ambos os tipos.

A seleção adversa decorreria do fato de uma das partes possuir mais informações que a outra acerca do objeto da demanda e da impossibilidade de essa outra obter a mesma informação. O risco moral no processo corresponderá à impossibilidade de uma das partes de antever o comportamento da outra parte por não possuir informações suficientes. Em ambos os casos, o que se espera é que as partes não produzam comportamentos oportunistas, considerando possuírem informações não disponíveis às demais partes.

A cooperação nos limites impostos pelo art. $6^{\circ}$ do NCPC implica em obrigações de ordem formal (respeito às formalidades processuais normativas), de ordem comportamental (não agir contra o processo, produzindo atos que impeçam ou dificultem o seu andamento) ou ainda de ordem objetal (necessidade de transparência).

Mesmo assim, sabemos que a falta de sanção específica é um obstáculo para a consecução dos objetivos da norma, mas devemos admitir que a ausência de cooperação pode provocar no juízo uma inoportuna antipatia à deslealdade, com consequência direta na interpretação constante dos elementos do processo, isto é, o ato de não cooperar pode não ter sanção direta, mas, indiretamente, pode implicar em uma maior rigorosidade do juiz em relação à interpretação do direito do infringente. 


\section{COOPERAÇÃO NO PROCESSO E RES PUBLICA}

No direito tributário, a cooperação precisa ser analisada com olhos na respublica, ou com relação à disponibilidade da coisa pública.

Assim, é relevante analisar esses argumentos de que a cooperação não se aplicaria à administração pública, que não pode transigir com o interesse público, decorrência do princípio do direito administrativo da indisponibilidade do interesse público. Lembremo-nos, ainda, que a Lei Complementar (LC) n. 101/2000 (Lei de Responsabilidade Fiscal) estabelece regras claras acerca da renúncia de receitas e da responsabilidade da gestão fiscal.

Por outro lado, é preciso apontar que cooperação não implica renunciar aos créditos tributários. Aliomar Baleeiro ${ }^{5}$ tangenciou a questão ao discutir o conceito de transação constante do Código Tributário Nacional (CTN), assim expondo:

O próprio art. 171 conceitua transação, empregando o vocábulo no sentido jurídico e não vulgar de negócio qualquer, [...] mas com o conteúdo de ato jurídico específico no qual um litígio entre os interessados pode ser regulado e extinto mediante ajuste e concessões recíprocas.

Ato jurídico, porque modifica e extingue obrigações preexistentes, e não contrato, apesar de prestigiosas opiniões em contrário, porque não cria tais obrigações.

Entendo que o trecho é relevante porque se o poder público puder transacionar, poderá cooperar.

Paulo de Barros Carvalho ${ }^{6}$ aponta o seu entendimento acerca da transação:

O princípio da indisponibilidade dos bens públicos impõe seja necessária previsão normativa para que a autoridade competente possa entrar no regime de concessões mútuas, que é da essência da transação. Os sujeitos do vínculo concertam abrir mão de parcelas de seus direitos, chegando a um denominador comum, teoricamente interessante para as duas partes, e que propicia o desaparecimento simultâneo do direito subjetivo e do dever jurídico correlato. Ao contrário do que sucede no direito civil, em que a transação tanto previne como termina o litígio, nos quadrantes do direito tributário só se admite

5 BALEEIRO, Aliomar. Direito Tributário Brasileiro. 11. ed. atual. por Misabel Abreu Machado Derzi. Rio de Janeiro: Forense, 1999. p. 904-905.

6 CARVALHO, Paulo de Barros. Curso de direito tributário. 6. ed. São Paulo: Saraiva, 1993. p. 308. 
a transação terminativa. Há de existir litígio para que as partes, compondo seus mútuos interesses, transijam. Agora, divergem os autores a propósito das proporções semânticas do vocábulo litígio. Querem alguns que se trate de conflito de interesses deduzido judicialmente, ao passo que outros estendem a acepção a ponto de abranger as controvérsias meramente administrativas. Em tese, concordamos com a segunda alternativa.

Sendo possível a transação - respeitados os limites gerais de norma que a estabeleça, não objeto do presente artigo -, tenho que é possível alcançar a cooperação no processo de modo ainda mais efetivo.

O que se aproxima do princípio da cooperação imposto pelo NCPC com relação ao poder público são os princípios da legalidade, da moralidade e da eficiência administrativa, insculpidos no art. 37 da Constituição com redação dada pela Emenda Constitucional (EC) n. 19, de 4 de junho de 1998:

Art. 37. A administração pública direta e indireta de qualquer dos Poderes da União, dos Estados, do Distrito Federal e dos Municípios obedecerá aos princípios de legalidade, impessoalidade, moralidade, publicidade e eficiência. (grifos nossos)

Ante a vinculação dos atos administrativos, a autoridade competente deve agir atendo-se aos limites impostos pela norma, no dizer de Hely Lopes Meireles:?

Atos vinculados ou regrados são aqueles para os quais a lei estabelece os requisitos e condições de sua realização. Nessa categoria de atos, as imposições legais absorvem, quase que por completo, a liberdade do administrador, uma vez que sua ação fica adstrita aos pressupostos estabelecidos pelo Poder Público para a validade da atividade administrativa. Desatendido qualquer requisito, compromete-se a eficácia do ato praticado, tornando-se passível de anulação pela própria Administração, ou pelo Judiciário, se assim o requerer o interessado.

Conforme ensina Lourival Vilanova, " "O direito é o instrumento do Estado para realizar seus fins”. Então, só voltando um pouco ao que já passamos, o advogado

7 MEIRELLES, Hely Lopes. Direito administrativo brasileiro. 19. ed. São Paulo: Malheiros, 1994. p. 150.

8 VILANOVA, Lourival. Relação jurídica de direito público. Revista de Direito Público, Universidade de São Paulo, Instituto de Direito Público. v. 18, n. 74, abr.-jun. 1985. p. 47. 
público, o Procurador da Fazenda, pode em posse de informação que a parte não tem simplesmente concordar com a razão da parte contrária, com o contribuinte? Pode e faz.

Faz quando deixa de contestar algo que diuturnamente tem negado pelo judiciário mesmo que o faça com suporte nas listas de dispensas de contestar nos termos do art. 19 da Lei n. 10.522/2002, e poderá fazê-lo com base no princípio da cooperação:

Art. 19. Fica a Procuradoria-Geral da Fazenda Nacional autorizada a não contestar, a não interpor recurso ou a desistir do que tenha sido interposto, desde que inexista outro fundamento relevante, na hipótese de a decisão versar sobre: (Redação dada pela Lei no 11.033 , de 2004) [...].

Faz porque não há interesse público em condenar quem não pode ser condenado, ou melhor, condenar quem não deve, em termos tributários.

E o interesse público também se concentra na sua eficiência. Lucas Rocha Furtado ${ }^{9}$ discorre acerca do princípio constitucional da eficiência da administração pública:

A eficiência requer do responsável pela aplicação dos recursos públicos o exame da relação custo/benefício da sua atuação. O primeiro aspecto a ser considerado em termos de eficiência é a necessidade de planejamento, de definição das necessidades e a indicação das melhores soluções para o atendimento dessa necessidade pública. [...]

Por eficácia se deve entender o simples exame dos resultados. Realizada qualquer atividade estatal, deve-se buscar examinar em que medida aquela atividade gerou benefícios para a sociedade. [...]

O exame da eficácia requer do administrador público a avaliação dos resultados que as atividades por ele desenvolvidas geram em favor da sociedade. Se não houver benefícios, devem os responsáveis por referido órgão corrigir os rumos por meio da definição de novos modelos ou estratégias.

A efetividade, terceiro passo para a realização da economicidade, pressupõe o cumprimento das duas etapas anteriores. Como parte da eficiência, foram definidas as metas de atuação. No exame da eficácia, foram constatados os

9 FURTADO, Lucas Rocha. Curso de direito administrativo. Belo Horizonte: Fórum, 2007. p. 112-113. 
resultados da atividade administrativa. No exame da efetividade deve ser feita a comparação entre os objetivos ou metas que haviam sido fixadas por ocasião do planejamento e os resultados efetivamente alcançados. [...]

Não há, em todo o ordenamento jurídico, justificativa para a exclusão do princípio da eficiência do mundo do Direito e para a sua transferência para o campo da discricionariedade como mera opção de conveniência ou de oportunidade. No momento em que todos os que lidam com o Direito Administrativo se conscientizarem da necessidade de dar maior efetividade a todos os princípios, inclusive ao da economicidade, que compreende além da eficiência a efetividade e eficácia, o cidadão brasileiro talvez possa contar com serviços públicos compatíveis com a carga tributária praticada no nosso País.

Não bastasse isso, o interesse público não se encontra na derrota do contribuinte em relação ao poder público, mas na correção da aplicação da norma, na legalidade. Se o contribuinte tem razão, o advogado público deve colaborar para que se restabeleça o seu direito. Vale, nesse sentido, abrir um parêntese e lançar uma pequena discussão acerca da cooperação e da sua relação com a autocomposição, tão salutar em todos os sentidos.

O art. 190 do Código Adjetivo dispõe que "versando o processo sobre direitos que admitam autocomposição, é lícito às partes plenamente capazes estipular mudanças no procedimento para ajustá-lo às especificidades da causa e convencionar sobre os seus ônus, poderes, faculdades e deveres processuais, antes ou durante o processo" e que o juiz controlará a validade dessas convenções e somente recusará aplicá-las nos casos de nulidade ou de inserção abusiva em contrato de adesão ou no qual alguma parte se encontre em manifesta situação de vulnerabilidade.

Já expusemos que qualquer autocomposição não será possível em relação ao crédito tributário porque a administração pública não pode transigir com o interesse público. Contudo, o nosso questionamento não se refere a transigir com o crédito tributário, mas a estipular acordos em relação ao procedimento a ser adotado no processo. Digamos, estabelecer um acordo entre a Fazenda e o contribuinte para que este possa garantir o juízo de modo adequado à sua capacidade financeira, ou seja, reter um percentual específico do seu faturamento mensal, ou ainda depositar um montante determinado por mês etc.

Será isso possível? Tenho que sim, certo de que muitos têm opinião diversa. Mas a "mudança" é meramente procedimental, atende ao interesse das partes, não implica diminuir ou transigir em relação ao crédito e contribui para cumprir os princípios constitucionais da moralidade e da eficiência. 
Certamente o que se pretende é receber o crédito, não inviabilizar a atividade privada. Isso é cooperação.

\section{CONSIDERAÇÕES FINAIS}

O multifacetado folclorista Luís da Câmara Cascudo costumava dizer que "o Brasil não tem problemas, só soluções adiadas". Por óbvio a afirmação está longe de ser de todo uma inverdade num país que frequentemente adia decisões fundamentais e que usualmente adota soluções simplistas que acabam se refletindo somente nos próximos governos, quer seja por conta da relevância da decisão na política de governo, quer seja pela falta de capacidade de se examinarem as consequências futuras do ato, quer seja, simplesmente, por inconsequência.

As decisões públicas devem sempre atentar para o interesse público. Esse conceito se apresenta, por exemplo, na Constituição Federal quando esta pró́be que tributos tenham por efeito o confisco. Isso porque se o tributo serve, por um lado, para abastecer os cofres públicos para que o Estado possa cumprir seus misteres, por outro, não poderá tomar do contribuinte os valores necessários à sua subsistência, à manutenção do seu patrimônio e de suas atividades, afinal, o que pretende a administração é atingir o interesse comum com a tributação, jamais locupletar-se.

Além disso, o agente público não pode agir de modo irresponsável, mesmo que tenha competência e capacidade para tal. Isso é imoral e a moralidade é um dos cânones do sistema constitucional brasileiro.

Temos a convicção de que o ponto fulcral do que aqui expomos é a necessidade de uma mudança de cultura das partes no processo. Advogados e juízes precisam entender que no processo tributário o que se busca é satisfazer com eficiência o crédito tributário legítimo. Qualquer atitude em sentido contrário é prejudicial ao país, ferindo a segurança e a legalidade.

A função do jurista, nesse momento preliminar do NCPC, é fomentar a discussão, e a do advogado é insistir e praticar a cooperação. Não pretendo, entretanto, parecer ingênuo, como aquela história do Mário Américo, ex-massagista da seleção de 1958, que comprou um rádio do Garrincha pela metade do preço porque o atleta acreditou que o rádio só falava "sueco". Cultura não se muda com rapidez, o tempo é o tempero da mudança.

A vida não é feita de fair play, este é esporádico e subsidiário. O Barão de Coubertin morreu em Genebra, na Suíça, de um ataque fulminante do coração, pobre e isolado. 